\title{
High-throughput synthetic rescue for exhaustive characterization of suppressor mutations in human genes
}

\author{
Farah Kobaisi ${ }^{1,2,3} \cdot$ Nour Fayyad $^{3} \cdot$ Eric Sulpice $^{1} \cdot$ Bassam Badran $^{2} \cdot$ Hussein Fayyad-Kazan $^{2} \cdot$ Walid Rachidi $^{3}$. \\ Xavier Gidrol ${ }^{1}$
}

Received: 3 December 2019 / Revised: 21 March 2020 / Accepted: 30 March 2020 / Published online: 8 April 2020

(c) The Author(s) 2020

\begin{abstract}
Inherited or acquired mutations can lead to pathological outcomes. However, in a process defined as synthetic rescue, phenotypic outcome created by primary mutation is alleviated by suppressor mutations. An exhaustive characterization of these mutations in humans is extremely valuable to better comprehend why patients carrying the same detrimental mutation exhibit different pathological outcomes or different responses to treatment. Here, we first review all known suppressor mutations' mechanisms characterized by genetic screens on model species like yeast or flies. However, human suppressor mutations are scarce, despite some being discovered based on orthologue genes. Because of recent advances in high-throughput screening, developing an inventory of human suppressor mutations for pathological processes seems achievable. In addition, we review several screening methods for suppressor mutations in cultured human cells through knock-out, knock-down or random mutagenesis screens on large scale. We provide examples of studies published over the past years that opened new therapeutic avenues, particularly in oncology.
\end{abstract}

Keywords Suppressor mutation $\cdot$ Genetic screening $\cdot$ Cell phenotype $\cdot$ Synthetic rescue

\section{Introduction}

Genetic information encoded by the DNA should be preserved and faithfully transmitted across generations. This process is essential for determining the genetic composition of a species. Therefore, any mutation can alter the life of the affected species. Mutations range from nonsense, missense or frameshifts. These alterations' outcomes can change the functionality of encoded proteins or block their translation generating a diseased phenotype [1].

However, mutation is a double-edged sword. First, random mutations are the basis of evolution and organism adaptation to the environment, an aspect not discussed here

Xavier Gidrol

xavier.gidrol@cea.fr

1 University of Grenoble Alpes, CEA, INSERM, IRIG-BGE U1038, 38000 Grenoble, France

2 Laboratory of Cancer Biology and Molecular Immunology, Faculty of Sciences I, Lebanese University, Hadath, Lebanon

3 University of Grenoble Alpes, SYMMES/CIBEST UMR 5819 UGA-CNRS-CEA, IRIG/CEA-Grenoble, Grenoble, France
[2]. Second, deleterious mutations have a counterpart: suppressor mutations. Assuming a primary mutation creates a diseased phenotype, a new mutation(s) can reverse its effect to generate a wild-type or less severe phenotype and, thus, is defined as synthetic rescue [3]. Synthetic lethality, on the contrary, involves cell death arising from the combination of loss of function mutations in at least two genes where the loss of function in any gene individually does not contribute on its own to cell death. This can be beneficial in identifying tumor vulnerabilities. Suppressor mutations have been found by genetic screening in yeast, flies and worms, enabling the understanding of genetic interactions occurring during development $[4,5]$. The existence of secondary mutations may explain how some individuals appear healthy despite harboring disease-causing mutations [6]; while, on the other hand, some patients show resistance to treatments [7]. For example, a secondary mutation in fetal globin genes can ameliorate the effects of $\beta$ globin gene mutation, modifying the severity of sickle cell anemia [8]. In addition, a mutation in solute carrier family 30 member 8 (SLC30A8), which encodes an islet zinc transporter, decreases the risk of diabetes by $65 \%$ even in the presence of risk factors such as obesity [9]. The discovery of human suppressor mutations 
is still an emerging field with little documentation. Suppressor mutations are classified according to whether they are located in the same gene as the primary mutation to be intragenic or not hence extragenic.

With the growth of genome-wide association studies (GWAS), characterization of synthetic rescue mutations in humans would be valuable to comprehend phenotypic outcomes in patients and create new therapeutic strategies based on synthetic rescue. Moreover, due to recent advances in cell phenotype-based screening, it is only logical that such approaches are used for the identification of suppressor mutations. The screening methods rely on CRISPR-Cas9, RNAi, insertional mutagenesis and chemical screens combined with cell phenotype quantification methods [10-13].

\section{Classification of suppressor mutations}

\section{Intragenic suppression}

Intragenic suppression refers to the counteraction of an altered phenotype by a suppressor mutation located in the same gene as the primary mutation [14]. The classification is divided into true and pseudo-revertant mutations.

\section{True revertant}

A single base modification caused by a primary mutation is completely reversed to the wild-type sequence due to a suppressor mutation at the same position [15] (Fig. 1a) that restores the wild-type amino acid sequence. However, suppressor mutation does not necessarily restore the same DNA due to the redundancy of the genetic codon (Fig. 1b). This was reported in Caenorhabditis elegans by Novelli et al., who found that a glutamine to proline mutation in the collagen processing protease (dpy-31) was reverted back to the wild-type phenotype [16].

\section{Pseudo-revertant}

The function of the gene product will be partially or fully restored even if the wild-type sequence is not restored. The suppressor mutation produces a modified DNA or amino acid sequence that can still carry on the functional or structural characteristics of the wild-type gene [14]. Pseudoreversion is achieved through various mechanisms.

Base modification A single base change created can be corrected by another base modification either in the same codon or nearby. This modified gene codes for a different amino acid, but the resulting product can still restore the functionality of the original protein. The different base modifications can occur either in the same codon and the same (a) Conservation of DNA and amino acid sequence

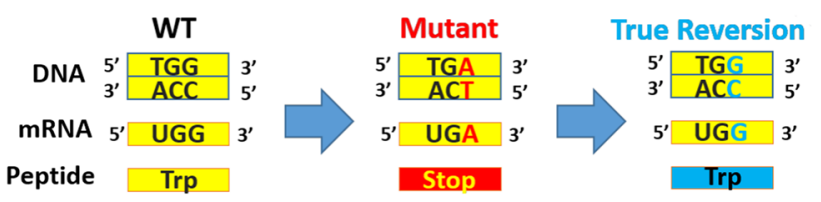

(b) Conservation amino acid sequence

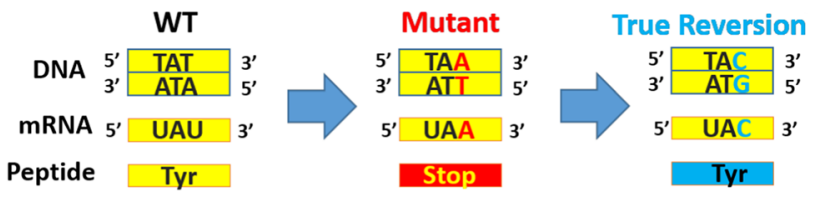

Fig. 1 True Revertant Intragenic Suppression. The primary and secondary mutations occur in the same codon and at the same level, the nucleotide level. a A mutation that changes a guanine nucleotide into an adenine nucleotide can lead to the conversion of an encoded amino acid from tryptophan into a stop codon. A true reversion mutation can change the sequence back to tryptophan with an adenine mutated to guanine such that tryptophan replaces the stop codon. Thus, the DNA and amino acid sequences are conserved. b In another scenario, a mutation of thymine to adenine changes the tyrosine amino acid to yield a stop codon. A true reversion mutation that changes the adenine to cytosine will enable the conversion of the stop codon back to tyrosine, thereby conserving the amino acid sequence alone. $W T$ wild type, $\operatorname{Tr} p$ tryptophan, $T y r$ tyrosine

or different nucleotide or at different codons in the same gene [5] (Fig. 2a). Examples from C. elegans include the conversion into proline amino acids created by a primary mutation that changed a glutamine to serine in the $d p y-31$ gene. This reversion prevents the lethality induced by loss of function mutation of the latter gene [16]. Furthermore, several second-site missense mutations in the cell interaction $g l p-1$ gene promote the reversion of the primary temperature-sensitive missense mutation [17].

Frameshift mutation They involve changes in the reading frame due to the insertion or deletion of nucleotides. Addition of a nucleotide that results in a detrimental change to the reading frame can be restored by a deletion mutation nearby that restores the reading frame [18] (Fig. 2b).

Altered splicing Multiple splice variants genes demonstrate altered splicing where a mutation in one of the alternatively spliced exons can be suppressed by a mutation to the acceptor site near said exon omitting it (Fig. 2c). The perlecanencoding gene unc-52 exhibits altered splicing that reverts the effect of the primary mutation causing defects in myofilament assembly and in the attachment of the myofilament lattice to the muscle cell membrane [19]. This mechanism is utilized for the treatment of Duchenne Muscular Dystrophy in which antisense oligonucleotides mimic altered splicing 
(a) Base Modification



1) same codon, same nucleotide

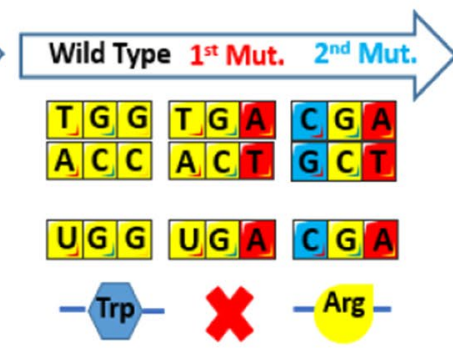

2) same codon, $\neq$ nucleotide

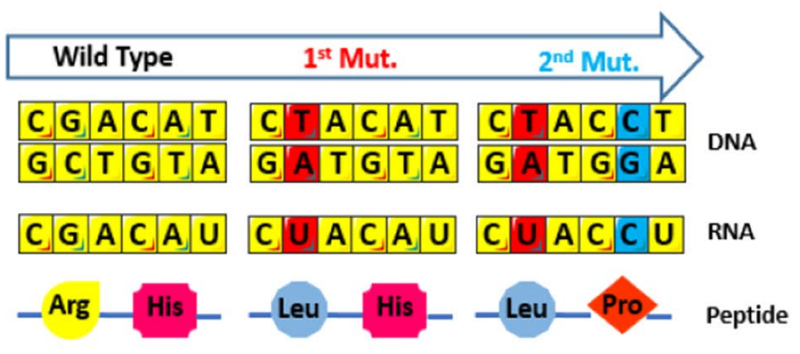

$3) \neq$ codon in same gene

(b) Frameshift



(c) Altered Splicing

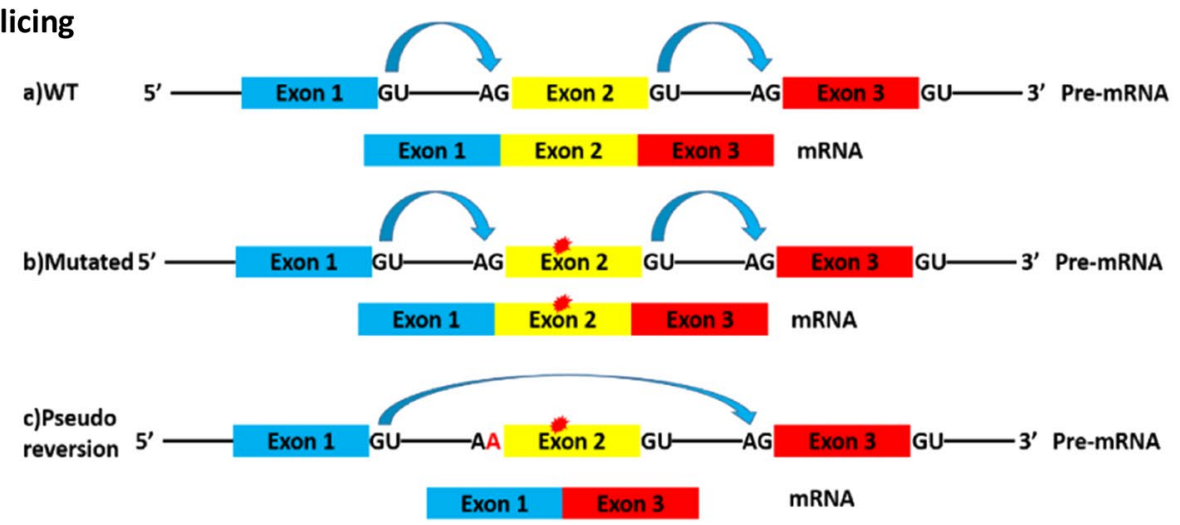

Fig. 2 Different forms of intragenic pseudo-reversion. Pseudo-reversion of primary mutation can occur by various types of secondary suppressor mutation. The first is a base modification further classified depending on the position of both mutations that can be in the (1) same codon and same nucleotide as the primary mutation resulting in a different translation output, from stop codon to cysteine for example, or (2) same codon but in a different nucleotide to produce arginine instead of a stop codon. In contrast, genes can be mutated at (3) different codons in the same gene to yield the amino acid proline near

suppressor mutation by biding to the site of mutation and induce the skipping of the mutated exon [20].

\section{Extragenic suppression}

The rescue of the mutant phenotype by a suppressor mutation located in a different gene is termed extragenic the mutated leucine. b A frameshift secondary mutation can partially restore the reading frame if the primary deletion mutation is counteracted by a suppressor insertion mutation. c Finally, altered splicing may mean that exons carrying mutations are skipped. This skipping can occur due to suppressor mutations altering the splice acceptor sites near the mutated exon that enable skipping and hence eliminate the effect of the primary mutation. WT wild type, Trp tryptophan, Cys cysteine, Arg arginine, Leu leucine, His histidine, Pro proline

suppression. This involves either informational or functional suppression.

\section{Informational suppression}

Informational suppression is allele-specific and genenonspecific [21] mutations involved in the transmission of genetic information from DNA to protein. They involve 
mutations that alter the machinery of DNA transcription, RNA processing, or protein translation. The genes responsible for stabilizing mRNAs or proteins can also influence the mutations that fall into this category where this stabilization may compensate for the poor functionality of a mutated product. The two genes involved in information suppression do not share a close functional relationship in a given developmental or pathological process.

Nonsense suppressor tRNA: translational suppression Nonsense mutations result from base modifications creating any of the three nonsense codons: UAA (ochre), UAG (amber), or UGA (opal) leading to termination of translation, hence partial or complete loss of gene function. However, suppression of this mechanism is enabled by nonsense suppressor tRNAs with anticodons that recognize stop codons and add amino acids at such sites to partially or fully restore protein function (Fig. 3a). A nonsense suppressor tRNA class with a mutation in the anticodon loop exists for the recognition of each type of the three stop codons [22]. For example, tRNA

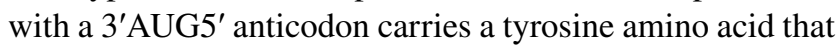
is added to the growing polypeptide when it encounters the 5'UAC3' codon. Mutation in this anticodon from 3'AUG5' to $3^{\prime}$ AUC5' results in a tRNA that still carries tyrosine but can now recognize the amber stop codon 5'UAG3' and add this tyrosine to the growing polypeptide chain instead of terminating translation (Fig. 3a). One downside of these mutated tRNAs is that they can no longer recognize their wild-type codons. However, tRNA genes are available in multiple copies across the genome; therefore, other copies can still code for the unmutated tRNA [23]. O'Neill et al. showed the presence of mutated tRNA genes by screening a human DNA library cloned in a bacteriophage with an opal suppressor tRNA probe [24].

Loss of NMD NMD refers to "nonsense mRNA decay" initiated by the presence of a premature termination codon (PTC) 50-55 nucleotides upstream of the final exon-exon junction and leads to the downregulation of the transcript via its degradation [25]. However, the absence of NMD ensures a longer half-life for the transcripts carrying this PTC, increasing the chance that they will be translated. This loss can be mediated by mutations at the NMD level, including mutations in mRNA decay-associated $S M G$ kinase genes, enabling the translation of the mutated mRNA and, thus, suppressing the effects of the primary nonsense mutation [5] (Fig. 3b). It should be noted that increasing the translation of disease-associated mRNA is utilized for the treatment of certain genetic disorders, including Duchenne muscular dystrophy, rendering the loss of NMD an appealing suppressor mechanism [26]. Loss of NDM was first identified in C. elegans following the creation of nonsense muta- tions by forward mutagenesis screens that yielded mutations in genes associated with NMD [27].

Modified splicing Unlike the altered splicing in pseudorevertant mutations, the effect of the primary mutation is suppressed by mutations at the level of the splicing machinery (Fig. 3c). In C. elegans, loss-of-function mutations in sтu genes encoding proteins homologous to mammalian spliceosome-associated factors lead to enhanced exons skipping, including the skipping of exons with primary mutations [28]. The mutated perlecan gene unc-52 is reportedly suppressed by loss-of-function mutations in the smu- 1 and $s m u-2$ genes in addition to its suppression by altered splicing.

Informational dosage suppression Dosage suppression involves elevated gene expression rather than a gene mutation to suppress the altered phenotype (Fig. 3d).

Overexpression of ribosomal subunits The overexpression of ribosomal subunits has counterbalancing outcomes. Certain studies found a correlation between genetic fitness and ribosomal composition, suggesting a role for ribosomal subunit stoichiometry in regulating translation or affecting the progression of the cell cycle [29]. However, another study attributed a different role for these proteins, suggesting that they are possible chaperones that increase the stability of the proteins harboring mutations and shielding them from degradation [30].

Protein turnover The overexpression of transcription factors leads to increased transcription of mutated genes. This increased gene expression increases the likelihood that the upregulated RNA will be translated [31].

Modulating protein stability or degradation Mutated mRNA can be translated to yield unstable proteins prone to degradation. Interfering with this degradation or stabilization of proteins can increase their half-lives, which may enable them to partially function, depending on the severity of the original mutation. J. Van Leeuwen et al. demonstrated that a genetic mutation in ubiquitin protein kinase san 1 annuls its role in targeting proteins' hydrophobic residues for proteasomal degradation [6]. In addition, overexpression of chaperones that stabilize the mutant protein increases the pool of active mutated proteins [31].

\section{Functional suppression}

Mutations can modulate the function of gene products by affecting their posttranslational modifications, localization or their interaction with either activators or inhibitors. Functional suppressors can help substitute or restore this modulated function via the alteration of proteins functionally 




(b) Loss of NMD

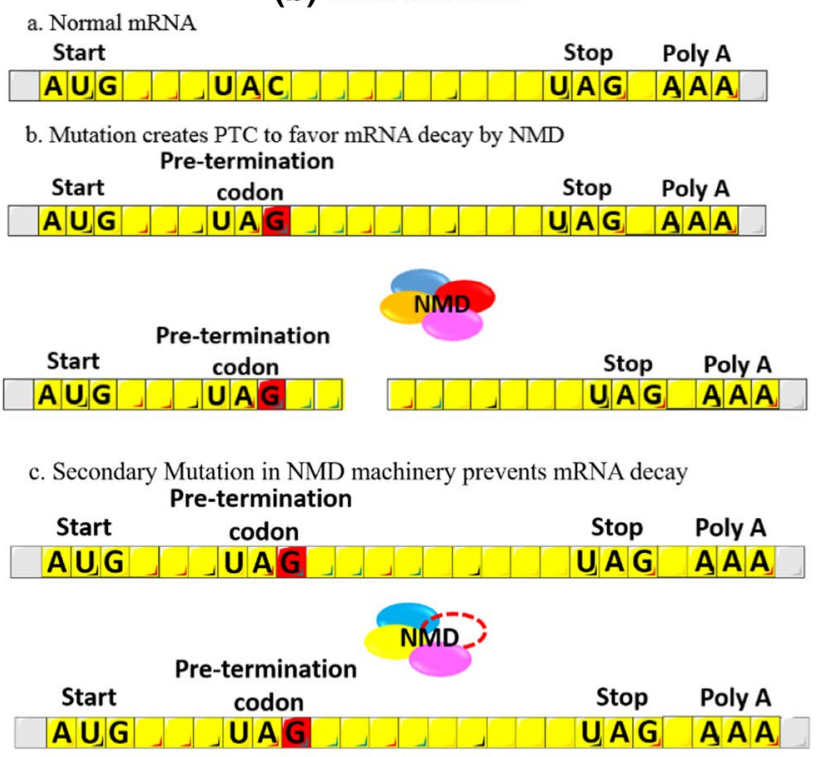

(c) Modified Splicing
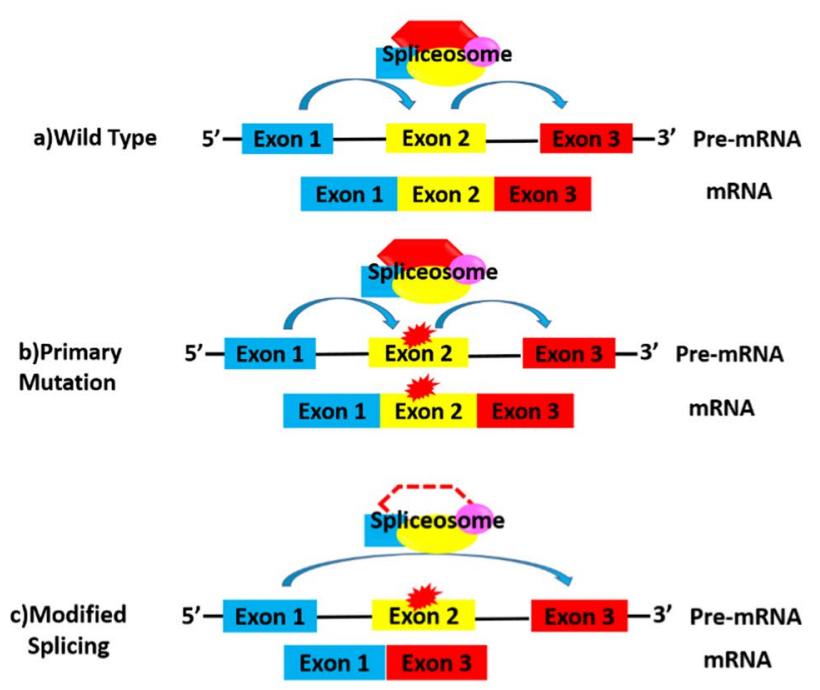

(d) Informational Dosage Suppression
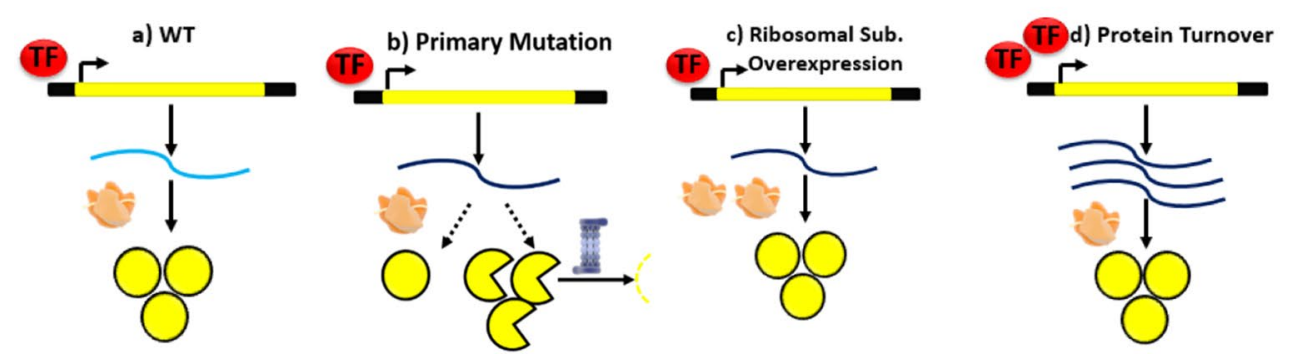

e) Protein Stability \& Degradation

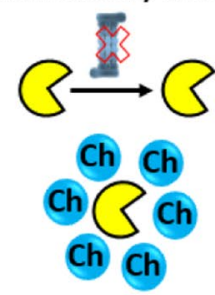

Fig. 3 Extragenic Informational Suppression. Informational suppression deals with any suppressor mutations that alter the transmission of genetic information form DNA to protein. (a) Nonsense suppressor tRNA. tRNA with the anticodon 3'UUC 5' carries a lysine amino acid to add to the growing polypeptide when it encounters the codon 5'AAG3'. Mutation of this codon from 5'AAG3' to 5'UAG3' results in a stop codon. However, a tRNA suppressor mutation that mutates a 3'AUG5' anticodon to 3'AUC5' results in a tRNA that still carries the same amino acid tyrosine but can recognize the 5'UAG3' stop codon and prevent the termination of translation. (b) Loss of NMD. A nonsense mutation can cause the mRNA to carry a premature termination codon (PTC) that targets it for degradation by NMD. However, a suppressor mutation in the NMD machinery can block degradation and prevent protein loss. (c) Modified splicing involves skipping the exons that carry mutations. This phenomenon occurs due to suppressor mutations that alter the spliceosome, which enables the mutated exon to be skipped, thus eliminating the effect of the primary mutation. (d) Informational dosage suppression. Primary mutations can either decrease the expression or code for modified proteins that are subjected to proteasomal degradation. Suppressor mutations can increase the expression of the mutated protein by overexpressing either ribosomal subunits or transcription factors. Another mechanism deals with protein stability and degradation whereby a mutation in proteasomes can protect the mutated protein from degradation, or the protein can be rescued by overexpressed chaperone proteins that stabilize the mutated protein. tRNA: transfer RNA, Pro: proline, Lys: lysine, Tyr: tyrosine, NMD: nonsense mediated mRNA decay, PTC: premature termination codon, TF: transcription factor, $\mathrm{CH}$ : chaperon 
related to the primary proteins [32]. Different classes of functional suppressors exist, and they are all gene specific.

Epistasis Signal transduction requires sequential steps initiated by receptor activation, second messengers, effectors and transcription factors. The modulation of one step can hinder message transmission. Epistasis involves additional mutations in a different step upstream or downstream, but in the same pathway, that can restore protein functionality [33]. This occurs in regulatory switch pathways alternating between "on" and "off" state where the primary and suppressor mutation often have antagonistic effects. For example, in the sequential pathway of signal $\rightarrow$ protein $1-\mathrm{I}$ protein $2-$ I protein 3 , the signal activates protein 1 , which in turn inhibits protein 2 to abolish its effect in the inhibition of protein 3 , thus rendering protein 3 active. A primary mutation that disrupts the function of protein 1 will block this pathway due to the constitutive activation of protein 2. However, an additional suppressor mutation to protein 2 enables the activation of protein 3 , although in a constitutive manner. The two mutations in this example scenario are loss-of-function mutations. Another possible mechanism for epistatic suppression in the same example pathway is the combination of a primary loss-of-function mutation in protein 1 and a simultaneous gain-of-function suppressor mutation in protein 3, reestablishing the pathway. Mutation in yeast cdc25, which encodes the guanine nucleotide exchange factor, prevents downstream Ras activation but can be suppressed either by a secondary loss of function mutation in GTPase activating protein Ira1, a known inhibitor of Ras activation, or by a gain-of-function mutation in Ras itself (Fig. 4a). Dosage suppression was also recorded where Ras overexpression suppresses cdc25 mutation [34]. In mice, the functional loss of Mdm2, a Trp53 negative regulator, can be suppressed by the functional loss of P53 [35].

Bypass suppression Bypass suppression genes belong to different pathways biochemically or genetically parallel. Here, the alteration of protein activity in a pathway is compensated by one of the two modifications of an alternative protein in a related but different pathway [36]. The first involves bypassing of protein 1 loss of functionality by the alteration of the specificity of protein 2 such that the alternate pathway is rewired to perform the function of protein 1 . In $E$. coli, mutations the alter the specificity of lactose permease permit the transport of maltose, despite the presence of a mutated maltose permease [37] (Fig. 4b).

Moreover, in yeast, the reduction of the mitochondrial membrane potential caused by the absence of mitochondrial ribosomal protein Mrpl3 is restored by the gain-of-function mutation in Atp1, an ATP synthase subunit [6]. The other model can be classified as both bypass and dosage suppressor because the amount of the alternate protein is the factor responsible for the compensation of the modified activity. The overexpression of protein 3 can overcome protein 1 mutation despite being of low constitutive activity at normal expression rate [38]. For instance, the overexpression of BRL1 involved in changing the nuclear membrane composition can suppress the inhibited nuclear protein import caused by a mutation in NUP116 [39] (Fig. 4b).

Interaction suppression Interaction suppression affects proteins belonging to the same complex and it is allele- and gene specific [14]. Mutations that change the shape or binding site of one protein prevent its complexation abrogating the complex's function. However, a suppressor mutation that creates a compensatory shape change in the second protein can help restore the lock-and-key interaction [40]. Another mechanism relies on the overexpression of another complex subunit that increases the recruitment ability of the mutated component without a compensatory change in the shape of the secondary protein [41]. The overexpression mass action will kinetically drive the formation of the complex, regardless of the decreased binding constant. Moreover, overexpression of a paralog can also compensate for this loss [42]. Finally, a gain-of-function mutation in one of the remaining complex subunits can reinstate the complex function by either stabilizing it or completely substituting the function of the originally mutated component [43]. In yeast, mutation in the DNA polymerase delta subunit Pol31 is suppressed by either the mutation in the catalytic subunit Pol3 of the DNA polymerase or by its overexpression [44] (Fig. 4c). Another example from yeast involves both Cdc2 kinase and $\mathrm{Cdc} 13$ cyclin, for which a suppressor mutation that introduces an additional contact surface between the two proteins help reestablish complex formation $[45,46]$.

\section{High content screening for suppressor mutations}

The relationship between genotype and phenotype has long been studied by genetic screens introducing genetic perturbation into cell or organism to investigate their effects on phenotype. Suppressor screens go one step further to identify modulators of an altered phenotype with an inborn genetic abnormality in an attempt to overcome the outcome of primary mutation.

In silico suppressor screen was performed by Das Sahu et al. It aimed to identify synthetic rescue (SR) mediators of resistance to immunotherapy by analyzing tumor transcriptomics and survival data of cancer patients. Several SR interactions in cancer cells resistant to therapy have been reported, some of which are rescuers of DNA methyl transferase (DNMT), which renders the cells resistant to killing by the DNMT1 inhibitor decitabine [7]. Another 


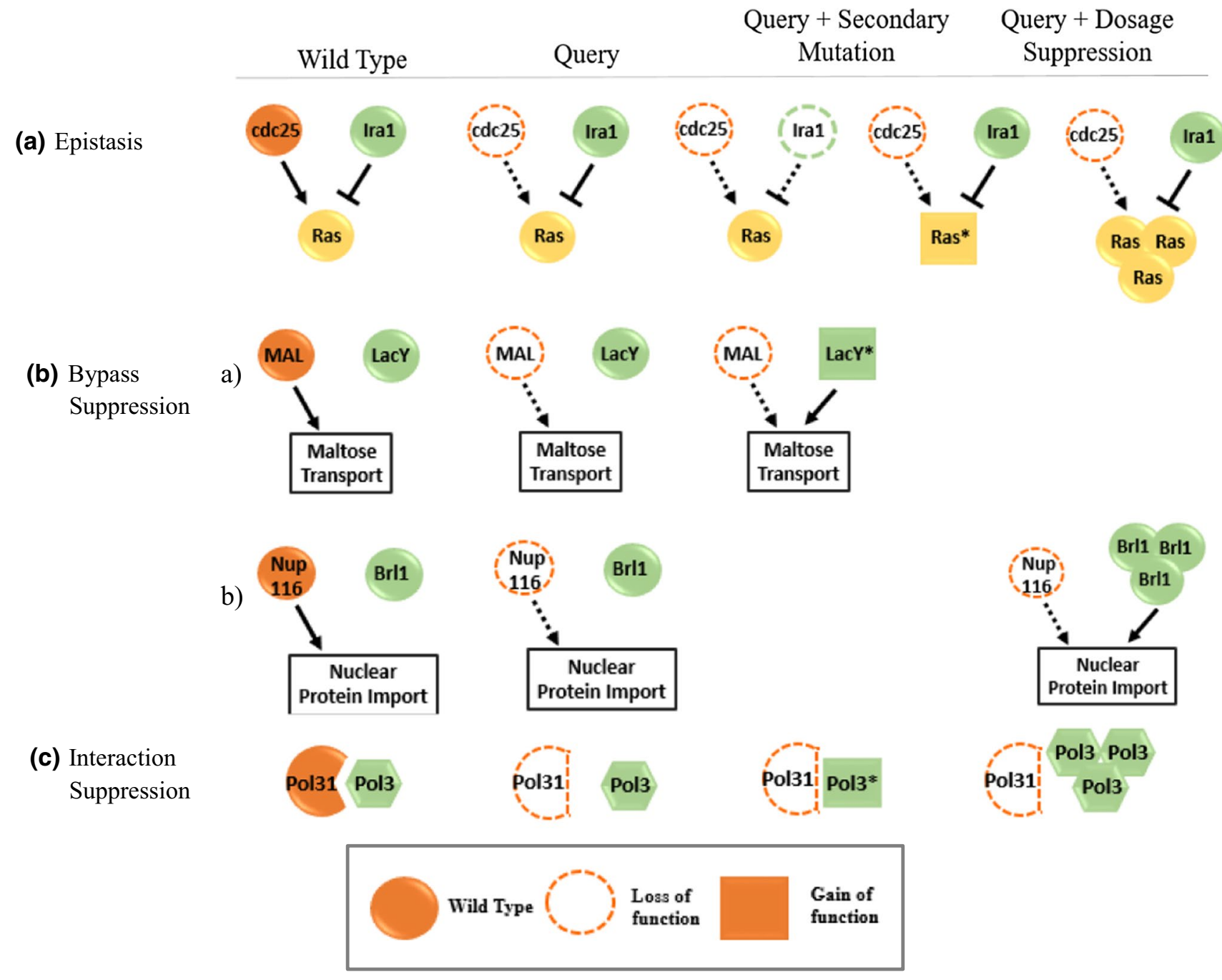

Fig. 4 Functional suppression: epistasis, bypass and interaction suppression. a Epistasis describes a suppressor mutation in a protein belonging to the same pathway as the protein that was primarily mutated. For example, a mutation in cdc25, a guanine nucleotide exchange factor, prevents downstream Ras activation but can be suppressed by either a secondary mutation in GTPase activating protein Ira1, a known inhibitor of Ras activation, or by a gain-of-function mutation in Ras itself. Dosage suppression was also recorded in which Ras overexpression can suppress the mutation of cdc25. b Bypass suppression involves two mutated genes that belong to different pathways that are functionally related. Mutations altering the specificity of lactose permease (LacY) permit the transport of malt-

algorithmic-based screening was carried out by Motter et al. who predicted secondary mutations in metabolic pathways reversing the growth defect of a primary metabolic one [47]. The utilization of this same approach to compare transcriptomes from patients with similar primary mutations but differing symptoms can help identify secondary suppressor mutations and synthetic rescuers. Nonetheless, other conventional screening approaches include CRISPR-Cas9, ose, despite the mutation to maltose permease (MAL). Another example is that of the overexpressed BRL1 involvement in changing the nuclear membrane composition to suppress the inhibited nuclear protein import that was induced by a mutation in Nup116. The latter mechanism can be categorized as dosage suppression. c Interaction suppression involves mutations in proteins that belonging to the same complex. For instance, the mutation in the DNA polymerase delta subunit Pol31 is suppressed by either the mutation in the catalytic subunit Pol3 of DNA polymerase or by its overexpression. Cdc25 guanine nucleotide exchange factor, Iral GTPase activating protein, $L a c Y$ lactose permease, $M A L$ maltose permease, $B R L 1$ Nucleus export protein, NUP116 nucleoprotein 116

RNAi, insertional mutagenesis and chemical-based screening (Table 1).

\section{CRISPR-based screening}

CRISPR-Cas9 screens can be conducted in either arrayed or pooled formats. In both cases, cells harboring a particular mutation are subjected to knock-out of different genes to assess the desired phenotype. In the arrayed format, a single 
gene is deregulated in each well and different phenotypes can then be investigated, such as death versus survival, or phenotypical changes at the single cell level [48]. In contrast, a pooled screen offers more high-throughput characteristics and delivers a massive library to cells that are then sorted based on a particular phenotype of interest. This sorting can be either a positive selection in which the perturbations that enable survival are enriched, or negative sorting where targets deplete cells from the population. The effects of genetic perturbations are determined by comparing the sgRNA profile. The latter selection is more laborious as it requires a highly sensitive readout. Nonetheless, following both selection techniques, DNA is extracted and PCR amplification of the sgRNA encoding regions is performed to be further on sequenced and mapped. This process identifies either the enriched or depleted genes [49] (Fig. 5a). It should be noted that CRISPR-Cas9 screens have recently evolved such that they can be used not only for knockdown screens but also for loss-of-function or even activation screens due to the different possible modifications to sgRNA or to Cas9, such as those that disable some of its activities and fuse it with various effectors [50]. Moder et al. aimed to find a suppressor mutation enhancing the viability of cells deficient in the Fanconi anemia pathway. They generated their own disease model by introducing a frame-shift mutation in FANCC by CRISP-Cas9, which led to the loss of its protein expression [51]. Loss of FANCC renders the cells hypersensitive to cross-linking agents such as mitomycin $\mathrm{C}$ (MMC). The cells were transfected with a pooled genome-scale CRISPRknockout library and then selected with MMC to identify suppressors that rescue $\triangle \mathrm{FANCC}$ hypersensitive phenotype. Moder et al. successfully identified several members of the BLM complex that is part of a multienzyme DNA helicase and bridged to the FA complex by FANCM [52].

Similarly, MUTYH gene suppression was determined to alleviate photosensitivity in cells harboring mutations in the nucleotide excision repair gene XPA. This mechanism was discovered through the combined chemical and CRISPR-Cas9 effects on a CRISPR-Cas9-created XPAdeficient cell model [53].

\section{RNAi-based screening}

Different forms of interfering RNAs are microRNA (miRNA), small interfering RNA (siRNA) or short hairpin RNA (shRNA). miRNAs are generally not used in screens due to their partial complementarity that permits them to target several transcripts [54]. siRNAs are synthetically produced and can be introduced to the cells directly or within a plasmid as shRNA.

When performing RNAi-based screens, one should first identify which type of interfering RNA best suits the screen. If short-term silencing is required, siRNA libraries are the right choice as they do not undergo replication and are diluted upon cell division. siRNA libraries are mainly delivered to cells by lipid particles [55]. Otherwise, for long-term and stable silencing, shRNA vectors that can be integrated into the genome and copied to the progeny are used. The utilized vectors could be either nonviral plasmids or retroviral, adenoviral, or lentiviral vectors [56].

Similar to CRISPR-Cas9-based screens, RNAi screens are performed in two formats. Both siRNA and shRNA vectors can be utilized in the arrayed format each targeting one gene per well [57]. Pooled format is carried out with shRNA transfected or transduced in a large cell population then selected according to a particular phenotype. This process is followed by PCR amplification and sequencing of the enriched shRNA. Additional DNA sequences can also be added to the vectors to act as barcodes easing the identification of hits. This technique can also be used in a microarray format in which normal and mutant cell populations are transduced with barcode-containing vectors that are linked to two distinct fluorochromes, each unique to a population. The hybridization of DNA to the barcode probes on a

Table 1 Pros and Cons of the different mutagenesis/gene expression alteration methods

\begin{tabular}{lll}
\hline Screening technique & Pros & Cons \\
\hline CRISPR-Cas9 & $\begin{array}{l}\text { Induces irreversible alteration into the DNA that is transmitted to } \\
\text { progeny } \\
\text { Enables alterations in transcribed and untranscribed regions } \\
\text { Engineers versatility in Cas protein }\end{array}$ & $\begin{array}{l}\text { PAM sequence restrictions } \\
\text { Target genes can be identified immediately }\end{array}$ \\
RNAi & $\begin{array}{l}\text { RNAi can be chemically modified } \\
\text { RNAi can be used as a therapeutic agent } \\
\text { No need for complex library design }\end{array}$ & $\begin{array}{l}\text { Can partially suppress genes such that they } \\
\text { are limited to knocking them down } \\
\text { Exhibits off-target effects }\end{array}$ \\
& Limited to transcribed regions \\
Chemical & No need for complex delivery techniques & Random insertion \\
& & Sequencing is necessary \\
& & Requires time-consuming target identification
\end{tabular}




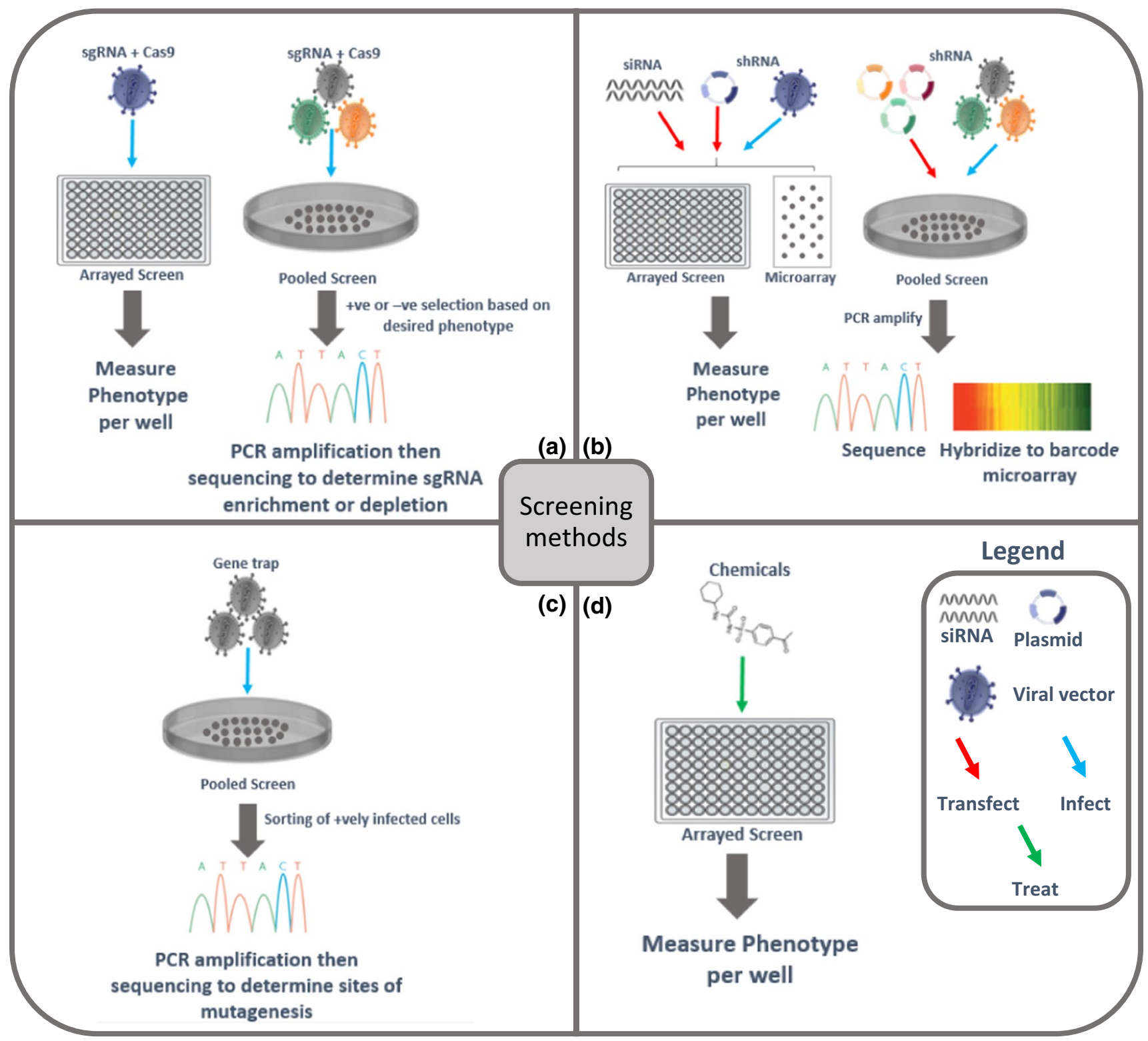

Fig. 5 Screening formats and methods. a CRISPR-Cas9 screening requires the delivery of the sgRNA and Cas- 9 through viral vectors to infect cells in either an arrayed format, followed by the detection of phenotypic changes in each well or in a pooled format in which cells are positively or negatively selected based on the phenotype of interest, followed by PCR amplification and sequencing for the identification of the sgRNA that is enriched or depleted. b RNAi screening can be done by transfecting siRNA or shRNA plasmids or by transducing cells with shRNA viral vectors. These three forms can be used in the arrayed or micro arrayed format to target one gene per well/ spot and measure readout. The pooled format utilizes shRNA in plasmids or viral vectors. The readout can be assessed by PCR amplification and sequencing of shRNA, or the barcode containing shRNA can be hybridized to the barcode microarray. c Insertional mutagenesis requires the transduction of cells in a pooled format with viral vectors carrying a gene trap cassette. Once the latter is inserted, the cells will be sorted if they are positively transduced and carry the phenotype of the insert. PCR amplification and sequencing will then enable the identification of sites of mutagenesis. d Chemical screens are initiated by treating cells in an arrayed format with one drug per well. The difficulty to track individually every drugs' effect and the possibility of interaction between drugs render it impossible for this assay to be carried out in a pooled format. Different phenotypic outputs can be assessed after the arrayed format treatment. CRISPR clustered regularly interspaced short palindromic repeats, $s g R N A$ single guide RNA, siRNA short interfering RNA, shRNA short hairpin RNA microarray will favor the comparison between the shRNA profile of the normal and mutant cells [58] (Fig. 5b). Microarray is not only used for assessing the output but can also be a screening format on its own. siRNAs, shRNA plasmids or even shRNA viral vectors can be arrayed on slides as individual drops, each targeting a specific gene. Cells can then be plated directly. After identifying the positions where 
a preferred phenotype is located, it can be simply linked to the target gene [59].

Luo et al. utilized a pooled genome-wide retroviral shRNA screen. The barcode-incorporated shRNA vectors were transfected into normal and colorectal cells with KRAS activating mutation followed by microarray-based comparison of shRNA profiles. They obtained several shRNA with anti-proliferative activity depleted from the population [60].

\section{Insertional mutagenesis-based screening (Gene trap)}

A gene trap cassette contains a promoterless reporter expressed only when inserted in the correct orientation in a transcriptional unit. It also contains one or several splice acceptor sites that render their expression conditional to the insertion of such cassette into introns or exons. Splicing enables the fusion of splice donor sites with the reporter splice acceptor creating transcriptional fusion and, thus, a fusion protein. Some insertions render the protein nonfunctional [61]. The procedure for insertional mutagenesis screening starts with the transduction of gene trap viruses. Expression of a reporter gene in the cassette allows the identification of the transduced cells to be FACS isolated. Phenotypic sorting is then performed to enrich the mutations favoring survival. The mutagenesis position is then determined by sequencing [62] (Fig. 5c).

Moder et al. performed a gene trap screen in parallel with the CRISPR-Cas 9 screen described earlier. They identified the loss of $\mathrm{NAD}(\mathrm{P}) \mathrm{H}$ :quinone oxidoreductase 1 (NQO1) as a possible suppressor mutation that alleviated the hypersensitivity of $\triangle$ FANCC HAP1 to MMC. Furthermore, BLM loss identified by CRISPR-Cas9 was also identified in the insertional mutagenesis screen [51]. A similar screen by Velimezi et al. led to the identification of USP48, that has a synthetic rescue interaction with FA genes [63]. The loss of USP48 enhanced the recruitment of homologous recombination proteins RAD51 and BRCA1 and reduced chromosomal instability.

\section{Chemical-based screening}

Chemical screens can be either phenotypic or target based. Phenotypic screening involves the treatment of cells with molecules that enable the identification of hits that mediate the formation of a desired phenotype. This methodology allows for selecting compounds directly active in the cells. In contrast, target-based screens are mostly focused on purified protein(s) and how the treatment with different compounds can affect it (their) functions or interactions. The limitation of the target-based method has to do with the fact that certain compounds may not be active within the cell or may interact with multiple targets depending on the cell context, thus abolishing the paradigm of one compound for one target [64]. Chemical screening consists of cell seeding followed by compound treatment and incubation (Fig. 5d). Screen variables include compound concentration and incubation duration. Screening is conducted in an arrayed format with different possible readouts [65].

The biggest drawback for cell-based chemical screening is target identification, especially for newly created active compounds. Several target deconvolution techniques have been developed for phenotypic screens, including affinity chromatography, activity-based protein profiling, analysis in silico or expression cloning [66].

Alli et al. conducted a chemical screen on a BRCA1mutated breast cancer cells deficient in base excision repair (BER). To visualize the reversal of the BER, the cells were transduced with an adenovirus coding for ODD and containing GFP. The expression of the reporter is only mediated if the damage is repaired due to treatment, signifying that the compound restored the repair process. The compounds identified were the FDA approved acetohexamide and benserazide [67] previously used in the treatment of diabetes and Parkinson; therefore, rerouting their use to potentially generate a new outcome would be relatively easy. In another screen, CRISPR-Cas9-generated XPA-deficient HAP1 cell lines were treated with a library of 290 FDA-approved drugs, and the hits corresponded to drugs that alleviate the photosensitivity and enable the repair of DNA damage following UV irradiation. Acetohexamide was identified for its NER repair enhancement capacity [53].

\section{Examining drug resistance by functional genetic screens}

The development of drug resistance in the course of treatment is a common issue that hinders patient recovery. For instance, pancreatic ductal adenocarcinoma with oncogenic KRAS mutation exhibits resistance to gemcitabine treatment mediated by the gain of function of DCLK1. The targeting of the later protein with anti-DCLK1 antibody inhibits in vivo tumorigenesis [68]. Thus, the identification of resistance mechanisms and mediators is of great importance. The latter seems possible with advances in screening technologies, especially in the fields of RNAi and CRISPR-Cas9. The most robust of such screens are survival-based positive selection screens. They are mediated by the introduction of either pooled shRNA or gRNA followed by the treatment with the drug in question for which the effect is hindered due to resistance. The identification of enriched sh/gRNA in these resistant cells enables the determination of possible targets for inhibition [69]. It is worth noting that the arrayed format of these screens is also effective for identifying resistance targets. 
For example, in a synthetic lethal experiment, treatment with AKT kinase inhibitor combined with a kinome RNAi library screening helped to identify kinases involved with AKT for the mediation of survival, including inositol polyphosphate multikinase (IPMK). The latter can be targeted in combination with inhibited AKT to favor synergistic synthetic lethality [70]. Moreover, the involvement of PRC2 complex suppression in the mediation of resistance to BET inhibitors in Acute Myeloid Leukemia was also discovered by carrying out a pooled shRNA library targeting 626 chromatin-associated murine genes. The effect was mediated indirectly via the remodeling of regulatory pathways favoring the transcription of genes like Myc [71]. CRISPR-Cas9-based genome-wide screen in melanoma cells co-cultured with cytotoxic $\mathrm{T}$ cells identified the inhibition of members of the SWI/SNF chromatin remodeling complex, as sensitizers for T-cell-mediated tumor killing and reversion of immunotherapy resistance [72]. Moreover, gene trap screens have also been utilized in synergy with chemical treatment. Bigenzahn et al. reported, after introducing a gene trap cassette in BCR-ABL ${ }^{+}$leukemia cells, that the inactivation of LZTR1 enables resistance against several BCR-ABL inhibitors due to increased RAS activity [73]. One final approach for deciphering resistance mediators can be via the utilization of sequencing. RNA sequencing of prostate circulating cancer cells from patients treated with androgen receptor inhibitors compared to untreated counteracts revealed the involvement of non-canonical Wnt signaling in resistance facilitation [74].

\section{Conclusion}

Suppressor mutations have opened a new gateway for therapy. Instead of fixing mutations directly through genetic engineering, it is possible to find new targets whose suppression rescue diseased phenotype. Suppressor mutations can range from second-site mutations to those that modify alternate pathways to compensate for loss of protein functionality. Discovery of suppressors started in yeast, flies, C. elegans and continues to be investigated in humans. For instance, a recent genetic study, "The Resilience Project," focuses on screening a seemingly healthy population of people for disease-associated variations. Once identified, these resilient individuals will undergo further genetic and clinical characterization for the identification of disease suppressors [75]. Another screening-based project is Project Achilles that utilizes RNAi and CRISPR to silence individual genes in genomically characterized cancer cells to identify genes affecting survival by algorithms [76]. Nonetheless, the path for suppressor discovery is paved with advances in screening methods and readout analyses. As demonstrated by the limited number of examples described above, large-scale screening procedures offer a way to generate an exhaustive repertoire of synthetic interactions and even synthetic lethal interactions in humans. Such an exhaustive characterization would be valuable for understanding variance in patients carrying same deleterious mutations and resistance to cancer drug treatment [7]. Finally, a better prediction of synthetic rescue mediators in the human genome will open new therapeutic avenues whereby inhibition of a given protein may restore a wild-type phenotype to normalize a pathologic state.

Acknowledgements We would like to acknowledge Marie-Odile Fauvarque for corrections and comments.

Funding Farah Kobaisi is supported by a grant from the Lebanese University.

Open Access This article is licensed under a Creative Commons Attribution 4.0 International License, which permits use, sharing, adaptation, distribution and reproduction in any medium or format, as long as you give appropriate credit to the original author(s) and the source, provide a link to the Creative Commons licence, and indicate if changes were made. The images or other third party material in this article are included in the article's Creative Commons licence, unless indicated otherwise in a credit line to the material. If material is not included in the article's Creative Commons licence and your intended use is not permitted by statutory regulation or exceeds the permitted use, you will need to obtain permission directly from the copyright holder. To view a copy of this licence, visit http://creativecommons.org/licenses/by/4.0/.

\section{References}

1. Jia P, Zhao Z (2017) Impacts of somatic mutations on gene expression: an association perspective. Brief Bioinform 18:413-425

2. Fitzgerald DM, Rosenberg SM (2019) What is mutation? A chapter in the series: how microbes "jeopardize" the modern synthesis. PLoS Genet 15:e1007995. https://doi.org/10.1371/journ al.pgen.1007995

3. Guarente L (1993) Synthetic enhancement in gene interaction: a genetic tool come of age. Trends Genet 9:362-366

4. Forsburg SL (2001) The art and design of genetic screens: yeast. Nat Rev Genet 2:659-668

5. Hodgkin J (2005) Genetic suppression. WormBook, pp 1-13

6. van Leeuwen J, Pons C, Mellor JC, Yamaguchi TN, Friesen H, Koschwanez J, Usaj MM, Pechlaner M, Takar M, Usaj M, VanderSluis B, Andrusiak K, Bansal P, Baryshnikova A, Boone CE, Cao J, Cote A, Gebbia M, Horecka G, Horecka I, Kuzmin E, Legro N, Liang W, van LN, McNee M, San Luis BJ, Shaeri F, Shuteriqi E, Sun S, Yang L, Youn JY, Yuen M, Costanzo M, Gingras AC, Aloy P, Oostenbrink C, Murray A, Graham TR, Myers CL, Andrews BJ, Roth FP and Boone C (2016) Exploring genetic suppression interactions on a global scale. Science 354

7. Sahu AD, Lee JS, Wang Z, Zhang G, Iglesias-Bartolome R, Tian T, Wei Z, Miao B, Nair NU, Ponomarova O, Friedman AA, Amzallag A, Moll T, Kasumova G, Greninger P, Egan RK, Damon LJ, Frederick DT, Jerby-Arnon L, Wagner A, Cheng K, Park SG, Robinson W, Gardner K, Boland G, Hannenhalli S, Herlyn M, Benes C, Flaherty K, Luo J, Gutkind JS, Ruppin E (2019) Genome-wide prediction of synthetic rescue mediators 
of resistance to targeted and immunotherapy. Mol Syst Biol 15:e8323. https://doi.org/10.15252/msb.20188323

8. Galarneau G, Palmer CD, Sankaran VG, Orkin SH, Hirschhorn JN, Lettre G (2010) Fine-mapping at three loci known to affect fetal hemoglobin levels explains additional genetic variation. Nat Genet 42:1049-1051. https://doi.org/10.1038/ng.707

9. Flannick J, Thorleifsson G, Beer NL, Jacobs SB, Grarup N, Burtt NP, Mahajan A, Fuchsberger C, Atzmon G, Benediktsson R, Blangero J, Bowden DW, Brandslund I, Brosnan J, Burslem F, Chambers J, Cho YS, Christensen C, Douglas DA, Duggirala R, Dymek Z, Farjoun Y, Fennell T, Fontanillas P, Forsen T, Gabriel S, Glaser B, Gudbjartsson DF, Hanis C, Hansen T, Hreidarsson AB, Hveem $\mathrm{K}$, Ingelsson $\mathrm{E}$, Isomaa $\mathrm{B}$, Johansson $\mathrm{S}$, Jorgensen $\mathrm{T}$, Jorgensen ME, Kathiresan S, Kong A, Kooner J, Kravic J, Laakso M, Lee JY, Lind L, Lindgren CM, Linneberg A, Masson G, Meitinger T, Mohlke KL, Molven A, Morris AP, Potluri S, Rauramaa R, Ribel-Madsen R, Richard AM, Rolph T, Salomaa V, Segre AV, Skarstrand H, Steinthorsdottir V, Stringham HM, Sulem P, Tai ES, Teo YY, Teslovich T, Thorsteinsdottir U, Trimmer JK, Tuomi T, Tuomilehto J, Vaziri-Sani F, Voight BF, Wilson JG, Boehnke M, McCarthy MI, Njolstad PR, Pedersen O, Groop L, Cox DR, Stefansson K, Altshuler D (2014) Loss-of-function mutations in SLC30A8 protect against type 2 diabetes. Nat Genet 46:357-363. https://doi.org/10.1038/ng.2915

10. Sharma S, Petsalaki E (2018) Application of CRISPR-Cas9 based genome-wide screening approaches to study cellular signalling mechanisms. Int J Mol Sci 19:933

11. Willingham AT, Deveraux QL, Hampton GM, Aza-Blanc P (2004) RNAi and HTS: exploring cancer by systematic loss-of-function. Oncogene 23:8392-8400

12. Zambrowicz BP, Abuin A, Ramirez-Solis R, Richter LJ, Piggott J, BeltrandelRio H, Buxton EC, Edwards J, Finch RA, Friddle CJ, Gupta A, Hansen G, Hu Y, Huang W, Jaing C, Key BW Jr, Kipp P, Kohlhauff B, Ma ZQ, Markesich D, Payne R, Potter DG, Qian N, Shaw J, Schrick J, Shi ZZ, Sparks MJ, Van SI, Vogel P, Walke W, Xu N, Zhu Q, Person C, Sands AT (2003) Wnk1 kinase deficiency lowers blood pressure in mice: a gene-trap screen to identify potential targets for therapeutic intervention. Proc Natl Acad Sci USA 100:14109-14114

13. Schulte J, Sepp KJ, Wu C, Hong P, Littleton JT (2011) High-content chemical and RNAi screens for suppressors of neurotoxicity in a Huntington's disease model. PLoS ONE 6:e23841

14. Manson MD (2000) Allele-specific suppression as a tool to study protein-protein interactions in bacteria. Methods 20:18-34

15. Prelich G (1999) Suppression mechanisms: themes from variations. Trends Genet 15:261-266

16. Novelli J, Ahmed S, Hodgkin J (2004) Gene interactions in Caenorhabditis elegans define DPY-31 as a candidate procollagen C-proteinase and SQT-3/ROL-4 as its predicted major target. Genetics 168:1259-1273. https://doi.org/10.1534/genetics.104.027953

17. Lissemore JL, Currie PD, Turk CM, Maine EM (1993) Intragenic dominant suppressors of glp-1, a gene essential for cell-signaling in Caenorhabditis elegans, support a role for cdc10/SWI6/ankyrin motifs in GLP-1 function. Genetics 135:1023-1034

18. Erdeniz N, Dudley S, Gealy R, Jinks-Robertson S, Liskay RM (2005) Novel PMS1 alleles preferentially affect the repair of primer strand loops during DNA replication. Mol Cell Biol 25:9221-9231

19. Rogalski TM, Gilchrist EJ, Mullen GP, Moerman DG (1995) Mutations in the unc-52 gene responsible for body wall muscle defects in adult Caenorhabditis elegans are located in alternatively spliced exons. Genetics 139:159-169

20. Aoki Y, Nakamura A, Yokota T, Saito T, Okazawa H, Nagata T, Takeda S (2010) In-frame dystrophin following exon 51-skipping improves muscle pathology and function in the exon 52-deficient mdx mouse. Mol Ther 18:1995-2005. https://doi.org/10.1038/ mt.2010.186

21. Glass RE, Nene V, Hunter MG (1982) Informational suppression as a tool for the investigation of gene structure and function. Biochem J 203:1-13

22. Beier H, Grimm M (2001) Misreading of termination codons in eukaryotes by natural nonsense suppressor tRNAs. Nucleic Acids Res 29:4767-4782

23. Buvoli M, Buvoli A, Leinwand LA (2000) Suppression of nonsense mutations in cell culture and mice by multimerized suppressor tRNA genes. Mol Cell Biol 20:3116-3124

24. O'Neill VA, Eden FC, Pratt K, Hatfield DL (1985) A human opal suppressor tRNA gene and pseudogene. J Biol Chem 260:2501-2508

25. Raimondeau E, Bufton JC, Schaffitzel C (2018) New insights into the interplay between the translation machinery and nonsensemediated mRNA decay factors. Biochem Soc Trans 46:503-512

26. Finkel RS (2010) Read-through strategies for suppression of nonsense mutations in Duchenne/Becker muscular dystrophy: aminoglycosides and ataluren (PTC124). J Child Neurol 25:1158-1164

27. Hodgkin J, Papp A, Pulak R, Ambros V, Anderson P (1989) A new kind of informational suppression in the nematode Caenorhabditis elegans. Genetics 123:301-313

28. Spartz AK, Herman RK, Shaw JE (2004) SMU-2 and SMU-1, Caenorhabditis elegans homologs of mammalian spliceosomeassociated proteins RED and fSAP57, work together to affect splice site choice. Mol Cell Biol 24:6811-6823

29. Slavov N, Semrau S, Airoldi E, Budnik B, van Oudenaarden A (2015) Differential stoichiometry among core ribosomal proteins. Cell Rep. 13:865-873

30. Kabir MA, Sherman F (2008) Overexpressed ribosomal proteins suppress defective chaperonins in Saccharomyces cerevisiae. FEMS Yeast Res 8:1236-1244

31. Magtanong L, Ho CH, Barker SL, Jiao W, Baryshnikova A, Bahr S, Smith AM, Heisler LE, Choy JS, Kuzmin E, Andrusiak K, Kobylianski A, Li Z, Costanzo M, Basrai MA, Giaever G, Nislow C, Andrews B, Boone C (2011) Dosage suppression genetic interaction networks enhance functional wiring diagrams of the cell. Nat Biotechnol 29:505-511

32. Baryshnikova A, Costanzo M, Kim Y, Ding H, Koh J, Toufighi K, Youn JY, Ou J, San Luis BJ, Bandyopadhyay S, Hibbs M, Hess D, Gingras AC, Bader GD, Troyanskaya OG, Brown GW, Andrews B, Boone C, Myers CL (2010) Quantitative analysis of fitness and genetic interactions in yeast on a genome scale. Nat Methods 7:1017-1024

33. Avery L, Wasserman S (1992) Ordering gene function: the interpretation of epistasis in regulatory hierarchies. Trends Genet 8:312-316

34. Park W, Mosteller RD, Broek D (1997) Identification of a dominant-negative mutation in the yeast CDC25 guanine nucleotide exchange factor for Ras. Oncogene 14:831-836

35. Jones SN, Roe AE, Donehower LA, Bradley A (1995) Rescue of embryonic lethality in Mdm2-deficient mice by absence of $\mathrm{p} 53$. Nature 378:206-208

36. Tye BK, Sawyer S (2000) The hexameric eukaryotic MCM helicase: building symmetry from nonidentical parts. J Biol Chem 275:34833-34836

37. Shuman HA, Beckwith J (1979) Escherichia coli K-12 mutants that allow transport of maltose via the beta-galactoside transport system. J Bacteriol 137:365-373

38. Maruyama IN, Miller DM, Brenner S (1989) Myosin heavy chain gene amplification as a suppressor mutation in Caenorhabditis elegans. Mol Gen Genet 219:113-118

39. Liu G, Yong MY, Yurieva M, Srinivasan KG, Liu J, Lim JS, Poidinger M, Wright GD, Zolezzi F, Choi H, Pavelka N, Rancati 
G (2015) Gene essentiality is a quantitative property linked to cellular evolvability. Cell 163:1388-1399

40. Jarvik J, Botstein D (1975) Conditional-lethal mutations that suppress genetic defects in morphogenesis by altering structural proteins. Proc Natl Acad Sci USA 72:2738-2742

41. Prelich G (2012) Gene overexpression: uses, mechanisms, and interpretation. Genetics 190:841-854

42. Szamecz B, Boross G, Kalapis D, Kovacs K, Fekete G, Farkas Z, Lazar V, Hrtyan M, Kemmeren P, Groot Koerkamp MJ, Rutkai E, Holstege FC, Papp B, Pal C (2014) The genomic landscape of compensatory evolution. PLoS Biol 12:e1001935

43. Menne TF, Goyenechea B, Sanchez-Puig N, Wong CC, Tonkin LM, Ancliff PJ, Brost RL, Costanzo M, Boone C, Warren AJ (2007) The Shwachman-Bodian-Diamond syndrome protein mediates translational activation of ribosomes in yeast. Nat Genet 39:486-495

44. Hashimoto K, Nakashima N, Ohara T, Maki S, Sugino A (1998) The second subunit of DNA polymerase III (delta) is encoded by the HYS2 gene in Saccharomyces cerevisiae. Nucleic Acids Res 26:477-485

45. Booher R, Beach D (1987) Interaction between cdc13+ and $\mathrm{cdc} 2+$ in the control of mitosis in fission yeast; dissociation of the $\mathrm{G} 1$ and $\mathrm{G} 2$ roles of the cdc2+ protein kinase. EMBO J 6:3441-3447

46. Sandrock TM, O'Dell JL, Adams AE (1997) Allele-specific suppression by formation of new protein-protein interactions in yeast. Genetics 147:1635-1642

47. Motter AE, Gulbahce N, Almaas E, Barabási AL (2008) Predicting synthetic rescues in metabolic networks. Mol Syst Biol 4:168. https://doi.org/10.1038/msb.2008.1

48. Echeverri CJ, Perrimon N (2006) High-throughput RNAi screening in cultured cells: a user's guide. Nat Rev Genet 7:373-384

49. Zender L, Spector MS, Xue W, Flemming P, Cordon-Cardo C, Silke J, Fan ST, Luk JM, Wigler M, Hannon GJ, Mu D, Lucito R, Powers S, Lowe SW (2006) Identification and validation of oncogenes in liver cancer using an integrative oncogenomic approach. Cell 125:1253-1267

50. Xue HY, Ji LJ, Gao AM, Liu P, He JD, Lu XJ (2016) CRISPRCas9 for medical genetic screens: applications and future perspectives. J Med Genet 53:91-97

51. Moder M, Velimezi G, Owusu M, Mazouzi A, Wiedner M, da Ferreira SJ, Robinson-Garcia L, Schischlik F, Slavkovsky R, Kralovics R, Schuster M, Bock C, Ideker T, Jackson SP, Menche J, Loizou JI (2017) Parallel genome-wide screens identify synthetic viable interactions between the BLM helicase complex and Fanconi anemia. Nat Commun 8:1238

52. Deans AJ, West SC (2009) FANCM connects the genome instability disorders Bloom's Syndrome and Fanconi Anemia. Mol Cell 36:943-953

53. Mazouzi A, Battistini F, Moser SC, da Ferreira SJ, Wiedner M, Owusu M, Lardeau CH, Ringler A, Weil B, Neesen J, Orozco M, Kubicek S, Loizou JI (2017) Repair of UV-Induced DNA damage independent of nucleotide excision repair is masked by MUTYH. Mol Cell 68:797-807

54. Lam JK, Chow MY, Zhang Y, Leung SW (2015) siRNA Versus miRNA as therapeutics for gene silencing. Mol Ther Nucleic Acids 4:e252

55. Yang D, Buchholz F, Huang Z, Goga A, Chen CY, Brodsky FM, Bishop JM (2002) Short RNA duplexes produced by hydrolysis with Escherichia coli RNase III mediate effective RNA interference in mammalian cells. Proc Natl Acad Sci USA 99:9942-9947

56. Graat HC, Witlox MA, Schagen FH, Kaspers GJ, Helder MN, Bras J, Schaap GR, Gerritsen WR, Wuisman PI, van Beusechem VW (2006) Different susceptibility of osteosarcoma cell lines and primary cells to treatment with oncolytic adenovirus and doxorubicin or cisplatin. Br J Cancer 94:1837-1844
57. Moffat J, Grueneberg DA, Yang X, Kim SY, Kloepfer AM, Hinkle G, Piqani B, Eisenhaure TM, Luo B, Grenier JK, Carpenter AE, Foo SY, Stewart SA, Stockwell BR, Hacohen N, Hahn WC, Lander ES, Sabatini DM, Root DE (2006) A lentiviral RNAi library for human and mouse genes applied to an arrayed viral high-content screen. Cell 124:1283-1298

58. Brummelkamp TR, Fabius AW, Mullenders J, Madiredjo M, Velds A, Kerkhoven RM, Bernards R, Beijersbergen RL (2006) An shRNA barcode screen provides insight into cancer cell vulnerability to MDM2 inhibitors. Nat Chem Biol 2:202-206

59. Iorns E, Lord CJ, Turner N, Ashworth A (2007) Utilizing RNA interference to enhance cancer drug discovery. Nat Rev Drug Discov 6:556-568

60. Luo J, Emanuele MJ, Li D, Creighton CJ, Schlabach MR, Westbrook TF, Wong KK, Elledge SJ (2009) A genome-wide RNAi screen identifies multiple synthetic lethal interactions with the Ras oncogene. Cell 137:835-848. https://doi.org/10.1016/j. cell.2009.05.006

61. Springer PS (2000) Gene traps: tools for plant development and genomics. Plant Cell 12:1007-1020

62. Carette JE, Guimaraes CP, Wuethrich I, Blomen VA, Varadarajan M, Sun C, Bell G, Yuan B, Muellner MK, Nijman SM, Ploegh HL, Brummelkamp TR (2011) Global gene disruption in human cells to assign genes to phenotypes by deep sequencing. Nat Biotechnol 29:542-546

63. Velimezi G, Robinson-Garcia L, Munoz-Martinez F, Wiegant WW, Ferreira da Silva J, Owusu M, Moder M, Wiedner M, Rosenthal SB, Fisch KM, Moffat J, Menche J, van Attikum H, Jackson SP, Loizou JI (2018) Map of synthetic rescue interactions for the Fanconi anemia DNA repair pathway identifies USP48. Nat Commun 9:2280. https://doi.org/10.1038/s41467-018-04649-z

64. Swinney DC, Anthony J (2011) How were new medicines discovered? Nat Rev Drug Discov 10:507-519

65. Kaelin WG Jr (2005) The concept of synthetic lethality in the context of anticancer therapy. Nat Rev Cancer 5:689-698

66. Lee J, Bogyo M (2013) Target deconvolution techniques in modern phenotypic profiling. Curr Opin Chem Biol 17:118-126

67. Alli E, Solow-Cordero D, Casey SC, Ford JM (2014) Therapeutic targeting of BRCA1-mutated breast cancers with agents that activate DNA repair. Cancer Res 74:6205-6215

68. Qu D, Weygant N, Yao J, Chandrakesan P, Berry WL, May R, Pitts K, Husain S, Lightfoot S, Li M, Wang TC, An G, Clendenin C, Stanger BZ, Houchen CW (2019) Overexpression of DCLK1-AL increases tumor cell invasion, drug resistance, and KRAS activation and can be targeted to inhibit tumorigenesis in pancreatic cancer. J Oncol 2019:6402925. https://doi.org/10.1155/2019/64029 25

69. Hinterndorfer M, Zuber J (2019) Functional-genetic approaches to understanding drug response and resistance. Curr Opin Genet Dev 54:41-47. https://doi.org/10.1016/j.gde.2019.03.003

70. Morgan-Lappe S, Woods KW, Li Q, Anderson MG, Schurdak ME, Luo Y, Giranda VL, Fesik SW, Leverson JD (2006) RNAibased screening of the human kinome identifies Akt-cooperating kinases: a new approach to designing efficacious multitargeted kinase inhibitors. Oncogene 25:1340-1348

71. Rathert P, Roth M, Neumann T, Muerdter F, Roe JS, Muhar M, Deswal S, Cerny-Reiterer S, Peter B, Jude J, Hoffmann T, Boryń ŁM, Axelsson E, Schweifer N, Tontsch-Grunt U, Dow LE, Gianni D, Pearson M, Valent P, Stark A, Kraut N, Vakoc CR, Zuber J (2015) Transcriptional plasticity promotes primary and acquired resistance to BET inhibition. Nature 525:543-547. https://doi. org/10.1038/nature14898

72. Pan D, Kobayashi A, Jiang P, Ferrari de Andrade L, Tay RE, Luoma AM, Tsoucas D, Qiu X, Lim K, Rao P, Long HW, Yuan GC, Doench J, Brown M, Liu XS, Wucherpfennig KW (2018) A major chromatin regulator determines resistance of tumor cells 
to T cell-mediated killing. Science 359:770-775. https://doi. org/10.1126/science.aao1710

73. Bigenzahn JW, Collu GM, Kartnig F, Pieraks M, Vladimer GI, Heinz LX, Sedlyarov V, Schischlik F, Fauster A, Rebsamen M, Parapatics K, Blomen VA, Muller AC, Winter GE, Kralovics R, Brummelkamp TR, Mlodzik M, Superti-Furga G (2018) LZTR1 is a regulator of RAS ubiquitination and signaling. Science 362:1171-1177. https://doi.org/10.1126/science.aap8210

74. Miyamoto DT, Zheng Y, Wittner BS, Lee RJ, Zhu H, Broderick KT, Desai R, Fox DB, Brannigan BW, Trautwein J, Arora KS, Desai N, Dahl DM, Sequist LV, Smith MR, Kapur R, Wu CL, Shioda T, Ramaswamy S, Ting DT, Toner M, Maheswaran S, Haber DA (2015) RNA-Seq of single prostate CTCs implicates noncanonical Wnt signaling in antiandrogen resistance. Science 349:1351-1356. https://doi.org/10.1126/science.aab0917

75. Friend SH, Schadt EE (2014) Translational genomics. Clues from the resilient. Science 344:970-972. https://doi.org/10.1126/scien ce. 1255648
76. Gönen M, Weir BA, Cowley GS, Vazquez F, Guan Y, Jaiswal A, Karasuyama M, Uzunangelov V, Wang T, Tsherniak A, Howell S, Marbach D, Hoff B, Norman TC, Airola A, Bivol A, Bunte K, Carlin D, Chopra S, Deran A, Ellrott K, Gopalacharyulu P, Graim K, Kaski S, Khan SA, Newton Y, Ng S, Pahikkala T, Paull E, Sokolov A, Tang H, Tang J, Wennerberg K, Xie Y, Zhan X, Zhu F, Aittokallio T, Mamitsuka H, Stuart JM, Boehm JS, Root DE, Xiao G, Stolovitzky G, Hahn WC, Margolin AA (2017) A community challenge for inferring genetic predictors of gene essentialities through analysis of a functional screen of cancer cell lines. Cell Syst 5:485-497.e3. https://doi.org/10.1016/j.cels.2017.09.004

Publisher's Note Springer Nature remains neutral with regard to jurisdictional claims in published maps and institutional affiliations. 